\title{
Human glutathione S-transferase polymorphisms associated with prostate cancer in the Brazilian population
}

Renata Almeida de Sá1,2,3, Aline dos Santos Moreira ${ }^{2}$, Pedro Hernan Cabello ${ }^{1,5}$, Antonio Augusto Ornellas ${ }^{6,7}$, Eduardo Butinhão Costa ${ }^{1}$, Cintia da Silva Matos ${ }^{3,4}$, Gilda Alves ${ }^{3}$, Ana Hatagima ${ }^{1}$

${ }^{1}$ Laboratory of Human Genetics and ${ }^{2}$ Laboratory of Functional Genomics and Bioinformatics, Oswaldo Cruz Institute / Oswaldo Cruz Foundation; ${ }^{3}$ Laboratory of Applied Genetics, Hematology Service and ${ }^{4}$ Laboratory of Clinical Pathology, ${ }^{5}$ Brazilian National Institute of Cancer; Laboratory of Human Genetics, Grande Rio University (UNIGRANRIO); ${ }^{6}$ Urology Service of Brazilian National Institute of Câncer and ${ }^{7}$ Mário Kröeff Hospital, Rio de Janeiro, RJ, Brazil

\section{ABSTRACT}

Objective: To evaluate the influence of polymorphisms in GSTA1, GSTM1, GSTT1, and GSTP1 in the risk of developing Prostate Cancer (PCa) in a population of Rio de Janeiro and compare the distribution of allele and genotype frequencies of the polymorphisms analyzed in the present study population with other regions in the country and different ethnic groups.

Materials and Methods: We analyzed a sample of the Brazilian population, comprising 196 patients with PCa treated by the urology services of the Brazilian National Cancer Institute (INCA) and Mario Kroeff Hospital (HMK), and 208 male blood donors from the Clementino Fraga Filho Hospital, Federal University of Rio de Janeiro (UFRJ). The polymorphisms were determined in DNA, extracted from peripheral blood leucocytes using the Polymerase Chain Reaction and Restriction Fragment Length Polymorphism (PCR-RFLP).

Results: Our results showed that the distribution of polymorphisms can vary significantly according to the Brazilian region and ethnic groups. The distribution of allele and genotype frequencies of the polymorphism GSTA1 was statistically different between cases and controls. Genotypes (A / B + B / B) were associated with protection (OR $=0.61,95 \% \mathrm{CI}=0.40-0.92$ ) for $\mathrm{PCa}$ in comparison to genotype $\mathrm{A} / \mathrm{A}$.

Conclusion: The distribution of genotype frequencies of the polymorphism GSTA1 was statistically different between the case and control groups $(p=0.023)$, and the presence of genotypes A / B and B / B suggests a protective role against the risk of PCa compared to genotype A / A. This is the first study that reports the genotypic frequency of this polymorphism and its association with PCa in a Brazilian population sample.

\section{ARTICLE INFO}

\section{Key words:}

Population Groups; Prostatic

Neoplasms; Disease

Susceptibility; Glutathione

Int Braz J Urol. 2014; 40: 463-73

Submitted for publication:

December 10, 2013

Accepted after revision:

March 22, 2014

\section{INTRODUCTION}

Prostate Cancer ( $\mathrm{PCa}$ ) is the second most common type of cancer in men (1). The incidence of PCa may vary among different ethnic groups and countries. The lowest rates are found in the Asian countries and the highest in the USA, Canada, Sweden, Australia, and France (2). In 
Brazil, 68,800 new cases of PCa are estimated for 2014 (3).

The etiology of the PCa is still poorly understood and the lack of consistent results for markers of high penetrance suggests that susceptibility to PCa possibly involves the effects of multiple factors, including the interaction of low-penetrance genes associated with exposure to environmental factors (4). The biochemical basis for genetic susceptibility to environmental risks has been related to mutations in genes involved in the elimination of carcinogenic compounds in the body (5). Several polymorphic genes encoding enzymes involved in the biotransformation of carcinogens have been studied as potential modifiers of risk of prostate cancer, including genes of the family of glutathione S-transferases (GSTs) (6). GSTs are enzymes involved in phase II xenobiotic metabolism, characterized by the combination of hydrophobic and electrophilic compounds with glutathione, leading to more soluble compounds that can be excreted.

The GSTA1 (ID: 2938; 6p12.1) gene has two alleles, GSTA1 * A and GSTA1 * B, with 3 (three) SNPs (Single Nucleotide Polymorphisms) apparently linked (-567T, -69C, -52G and -567G, -69T, -52A, respectively). Although much is known about the polymorphism, the exact mechanism of how it affects gene expression has not been fully clarified yet, but it is known that the exchange of base $\mathrm{G}$ at A position - 52 gene prevents binding of transcription factor (Sp1) of the promoter site, resulting in lower expression of the gene GSTA1 (7). Polymorphisms associated with decreased expression of the GSTA1 enzyme can lead to a buildup of carcinogens in the body and increase the risk of developing cancer (8). The GSTM1 (ID: 2944; 1p13.3) gene is polymorphic and has three allelic variants GSTM1 *0, GSTM1 *A, and GSTM1 ${ }^{*} \mathrm{~B}$, which have been widely investigated in various types of cancer (9-11).

Alleles GSTM1 *A and GSTM1 *B encode metabolically active enzymes. The difference between these two alleles is the exchange of a base $\mathrm{G}$ to $\mathrm{C}$, the coding region at position 534 (G534C), so that there is a substitution of lysine for asparagine (Asn $\rightarrow$ Lys). This exchange does not affect the enzymatic function (12). The null allele, GSTM1
${ }^{*} 0$, is the result of deletion of the gene GSTM1 due to fusion of two homologous regions flanking the gene. Interest in GSTM1 has been stimulated by studies that suggest that homozygosity for GSTM1 ${ }^{*} 0$ is associated with an increased risk for various cancers, due to no protein expression (13-15). Similar to GSTM1 ${ }^{*} 0$, the GSTT1 (ID: 2952; 22q11.2) gene also has a null allele (GSTT1 *0). Despite the deficiency in the metabolism of carcinogenic compounds due to gene deletion, there is controversy about which allele (GSTT1 ${ }^{*} 0$ or GSTT1 positive) would be at risk for cancer because unlike GSTM1, GSTT1 can play a role in both detoxification and activation processes (16).

The GSTP1 (ID: 2950; 11q13.2) gene has a G $\rightarrow$ A transition at nucleotide 313 , causing a variation of isoleucine for valine at codon 105 (17). The substitution Ile105Val alters the kinetic properties of the enzyme with possible functional alteration in the detoxification process, which, in the event of prolonged exposure to carcinogens, could cause irreversible damage to DNA, favoring carcinogenesis $(14,18)$. This polymorphism has been extensively investigated, and studies have revealed that the genotype GSTP1 105 Val / Val may be associated with increased risk for PCa $(5,19,20)$.

We conducted a case-control study to investigate the influence of GSTA1 (rs 3957357), GSTM1, GSTT1, and GSTP1 I105V (rs 1695) genetic polymorphisms in the susceptibility to prostate cancer. Additionally, we developed a descriptive observational profile of these polymorphisms in a sample of the population of Rio de Janeiro and its comparison with other regions of the country and different ethnic groups.

\section{MATERIALS AND METHODS}

\section{Subjects}

The case group consisted of 196 adult patients between 42-80 years of age (mean $61.3 \pm$ 7.00) who were diagnosed with prostate cancer, confirmed by histological examination, and treated at the Urology Services of the Brazilian National Cancer Institute (INCA) and of Mario Kröeff Hospital (HMK), 110 and 86 individuals, respectively, between February 2006 and September 2008. The control group consisted of 208 men aged between 43-86 
years (mean $58.0 \pm 7.78$ ) recruited at the blood bank of INCA (66 individuals) and at the blood bank of Clementino Fraga Filho Hospital, Federal University of Rio de Janeiro (UFRJ) (142 individuals), from July 2006 to March 2009. All participants were given an explanation of the nature of the study, and informed consent was obtained. This study was approved by the ethics committee of INCA (registration\# 091/05). All institutions are mapped in the city of Rio de Janeiro. The sample power was calculated based on Zar, 1999 (21).

\section{Genotype analysis}

To determine the genetic polymorphisms, samples were collected from peripheral blood in EDTA tubes properly identified. The genomic DNA extraction was performed from lymphocytes from whole blood, following the protocol with phenol and chloroform (22). All polymorphisms were determined in genomic DNA using PCR following protocols previously described (Table-1). GSTA1 and GSTP1 I105V polymorphisms were determined by Polymerase Chain Reaction and Restriction Fragment Length Polymorphism (PCR-RFLP). The technique of allele-specific PCR was applied to determine the GSTM1 polymorphism with three primers: one common, specific for the intron 6 (sense), and the other two for the exon 7 (antisense), specific to the alleles GSTM1 * A and GSTM1 * B. A fragment of the $\beta$-globin with $268 \mathrm{bp}$ (primer forward CAA CTT CAT CCA CGT TCA CC and primer reverse GAA GAG CCA AGG ACA GGT AC) was co-amplified as internal control of the PCR reactions for GSTM1 and GSTT1. Negative controls containing all reagents in the reaction, except DNA, were included in all reactions in order to detect possible contamination of reagents. DNA products were separated by electrophoresis in a $1.5 \%$ agarose gel, at $80 \mathrm{~V}$ in $1 \mathrm{X} \mathrm{TAE}$ buffer (Tris-Acetate-EDTA). The identification of the DNA fragments after the enzymatic digestion was performed in $10 \%$ polyacrylamide gels at $180 \mathrm{~V}$ in 1X TBE buffer (Tris-Borate-EDTA) (23). In all digestions DNAs from positive controls (holders of the enzyme cleavage site) were included to verify the success of the reaction. After electrophoresis, the gels were stained with ethidium bromide and visualized under ultraviolet (UV) light. DNA fragment sizes were estimated by comparison with pBR322/
Hae III molecular weight marker (Uniscience ${ }^{\circledR}$ Brazil) (Figure-1).

\section{Statistical analysis}

Calculations of allele frequencies were performed using the maximum likelihood method. Tests for Hardy-Weinberg and the heterogeneity of the samples were made by using the chi-square tests $\left(\chi^{2}\right)$. The statistical program Epi Info version 6.0 was used to estimate the hazard ratio with a confidence interval of 95\%. The chi-square $\left(\chi^{2}\right)$ was also used to compare the frequencies of the alleles found in this study with the frequencies observed in other populations (literature data).

\section{RESULTS}

All polymorphisms were in Hardy-Weinberg equilibrium in the case and in the control populations (Table-2). Table- 3 shows the analysis of the association between GSTA1, GSTM1, GSTT1, and GSTP1 I105V polymorphisms and the risk for PCa. Interestingly, the results showed a statistically significant protective association between GSTA1 genotypes A / B + B / B and PCa (OR $=0.61,95 \%$ IC $0.40-0.92, p=0.018)$.

The analysis of the genotype distribution of GSTM1, GSTT1, and GSTP1 Ile105Val polymorphisms showed that the case and control populations were homogeneous with respect to these polymorphisms. Thus, the two groups were assembled (cases + controls) to form a single larger and more representative group of the population that was used for comparisons with literature data. GSTA1 for polymorphism allele frequency in comparison with the other populations was performed using only the control group, since the samples (cases and controls) were not homogenous. For GSTM1 and GSTT1 polymorphism comparison among the different ethnic groups, analysis of phenotypes (positive and null) was performed because the inability to distinguish between homozygous and heterozygous genotypes for the technique used did not allow us to count genes (Table-4).

The allele frequencies of GSTA1 (only the control group) and GSTT1 polymorphisms showed no statistically significant difference when compared 


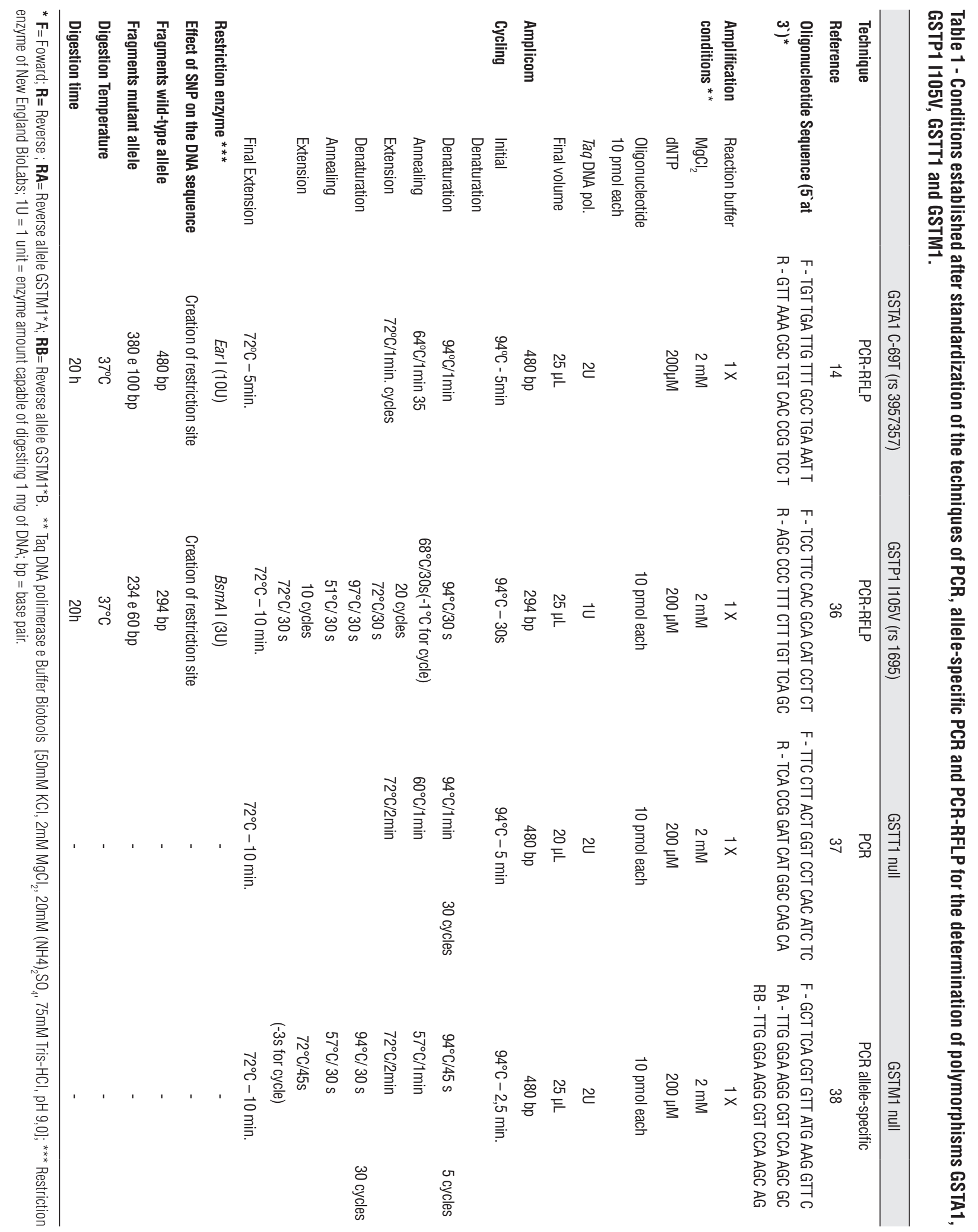


Figure 1 - Electrophoresis profile of polymorphisms GSTA1, GSTM1, GSTT1 and GSTP1.

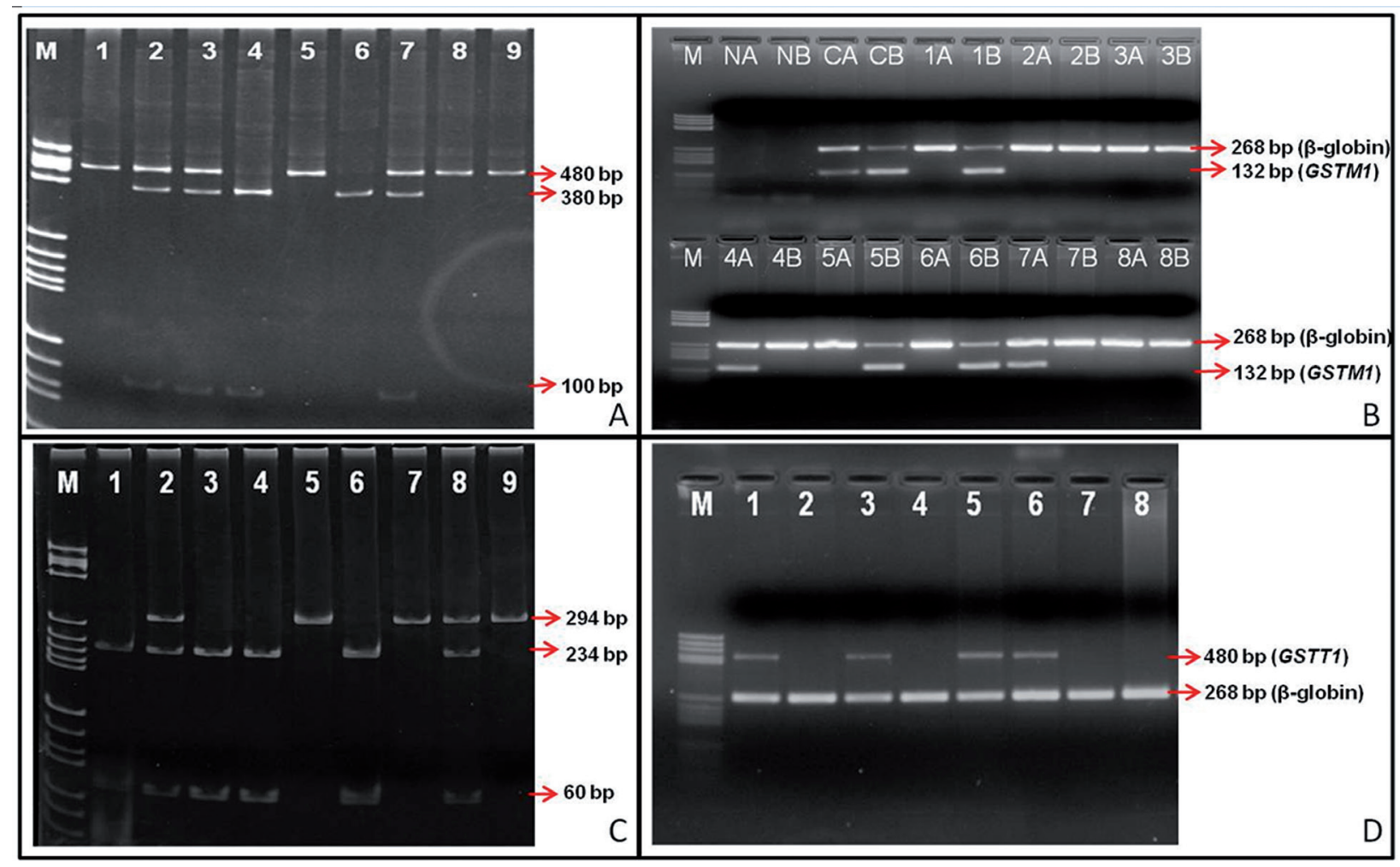

$\mathbf{M}=$ molecular weight marker pBR322/Hae III, A) Gel of $10 \%$ polyacrylamide with the GSTA1 products digested by Ear I. Lanes 1, 5, 8, and $9=$ homozygous for the wild type allele (A / A), 2, 3, and 7 = heterozygous (A / B) 4, and $6=$ homozygous for the mutant allele (B / B). B) Gel 2.5\% agarose with GSTM1 amplification products by allele-specific PCR. NA and NB = negative control; $C A$ and $C B=$ positive for the $A$ and $B$ alleles (genotype $A / B$ ) controls; 2,3 and $8=$ homozygous for the null allele (GSTM1 0/0); 1, 5 and $6=$ negative for allele $A$ and allele B for the positive (B phenotype / - ) individuals; Lanes 4, $7=$ positive for individuals negative for allele $A$ and B (phenotype A / -). C) Gel to 10\% polyacrylamide with the products of digestion with GSTP1 by BSMA I. Sample 5, 7 and $9=$ homozygous for the wild type allele (Ile / Ile) 2 and 8 = heterozygous (lle / Val), 1, 3, 4 and 6 = homozygous for the mutant allele (Val / Val) individuals. D) Agarose gel 2.5\% with GSTT1 amplification products. Lanes 2, 4, 7, and 8 = homozygous for the null allele (null genotype) individuals; $1,3,5$, and $6=$ subjects with at least one active allele for the gene GSTT1 (T / T or T / 0 )

to the frequencies of different populations of Caucasians and African-Americans, differing only in the Japanese population. The frequency of GSTM1 genotype frequencies varied significantly in Caucasians, African-Americans, and Asians while the allele frequency of the GSTP1 I105V polymorphism was unique, and showed a statistically significant difference in relation to the frequencies observed in other ethnic groups, with the exception of another population, the city of Sao Paulo (Table-4).

\section{DISCUSSION}

The metabolism of xenobiotic compounds is one of the most versatile mechanisms for cell protection. GSTs belong to a multigene family of dimeric enzymes that catalyze the conjugation of a number of carcinogens and endogenous compounds. Furthermore, studies suggest that GSTs are involved in the intracellular transport of steroid hormones (24). The cumulative exposure over a lifetime to androgens, androgen metabolites, and carcinogenic products can develop PCa in men who are genetically predisposed (25). Thus, the identification of genetic markers that are actually associated with initiation and progression of prostate tumors would enable the identification of men at risk for $\mathrm{PCa}$, allowing the development of preventive strategies for this cancer.

This study presents the first data on the frequency of GSTA1*A (-567T, -69C, -52G) and GSTA1*B (-567G, -69T, -52A) polymorphisms in 
Table 2 - Analysis of Hardy-Weinberg equilibrium for the genetic sample of controls and patients with PCa polymorphisms.

\begin{tabular}{|c|c|c|c|c|}
\hline Genotypes & Observed & Expected & $\chi_{1}^{2}$ & $p$ \\
\hline \multicolumn{5}{|l|}{ Controls } \\
\hline GSTA1 A/A & 76 & 79.147 & \multirow{3}{*}{0.917} & \multirow{3}{*}{0.338} \\
\hline$A / B$ & 99 & 92.706 & & \\
\hline$B / B$ & 24 & 27.147 & & \\
\hline GSTM1 0/0 & 87 & 83.830 & & \\
\hline$A /-$ & 70 & 73.171 & \multirow{2}{*}{1.393} & \multirow{2}{*}{0.238} \\
\hline $\mathrm{B} /-$ & 32 & 35.171 & & \\
\hline$A / B$ & 15 & 11.829 & \multirow{4}{*}{0.000} & \multirow{4}{*}{0.999} \\
\hline GSTP1 I/I & 85 & 85.043 & & \\
\hline IN & 96 & 95.914 & & \\
\hline V/N & 27 & 27.043 & & \\
\hline \multicolumn{5}{|l|}{ Patients } \\
\hline GSTA1 A/A & 99 & 101.434 & \multirow{3}{*}{0.741} & \multirow{3}{*}{0.389} \\
\hline$A / B$ & 84 & 79.133 & & \\
\hline$B / B$ & 13 & 15.433 & & \\
\hline GSTM1 0/0 & 80 & 81.205 & \multirow{4}{*}{0.285} & \multirow{4}{*}{0.593} \\
\hline$A /-$ & 88 & 86.795 & & \\
\hline $\mathrm{B} /-$ & 21 & 19,795 & & \\
\hline$A / B$ & 7 & 8.205 & & \\
\hline GSTP1 I/I & 73 & 76.563 & \multirow{3}{*}{1.179} & \multirow{3}{*}{0.277} \\
\hline I/N & 99 & 91.875 & & \\
\hline VN & 24 & 27.562 & & \\
\hline
\end{tabular}

$\chi^{2}{ }_{1}=$ chi-square with one degree of freedom.

a Brazilian population. The analyses revealed that the genotype frequencies were significantly different between cases and controls $(p=0.023)$, suggesting an association between the GSTA1 polymorphism and the risk of PCa (OR $=0.61,95 \%$ $\mathrm{CI}=0.40$ to 0.92 ) (Table-2). Previously, a case-control study (190 patients with PCa and 294 controls) in Japan found no statistically significant association in the overall analysis (14). However, after conducting an analysis stratified by smoking, they observed among smokers a higher risk for $\mathrm{PCa}$ associated with genotypes $\mathrm{A} / \mathrm{B}$ and $\mathrm{B} / \mathrm{B}(\mathrm{OR}=1.72,95 \% \mathrm{CI}=1.01$ to 2.72$)$. It was reported that a GSTA1 enzyme is efficient in the detoxification of compounds derived from tobacco, such as 2-amino-1-methyl-6-phenylimidazo [4,5$\beta]$ pyridine (PhIP) (26). Therefore, GSTA1 possibly plays an important role in protecting DNA against compounds derived from tobacco. Although this observation requires further study, the effect of smoking may be more important for susceptible populations such as those with a higher frequency 
Table 3 - Analysis of association between genetic polymorphisms and the risk of Prostate Cancer.

\begin{tabular}{ccccc}
\hline Genotypes & Cases & Controls & OR(IC 95\%) & P (Yates) \\
\hline GSTA1 A/A & 99 & 76 & 1 & \\
A/B & 84 & 99 & $0.65(0.42-1.01)$ & 0.056 \\
B/B & 13 & 24 & $0.42(0.19-0.92)$ & 0.028 \\
A/B + B/B & 97 & 123 & $0.61(0.40-0.92)$ & 0.018 \\
GSTM1 Positive & 116 & 117 & 1 & 0.787 \\
Null & 80 & 87 & $0.93(0.61-1.41)$ & \\
GSTT1 Positive & 161 & 161 & $0.74(0.44-1.25)$ & 0.289 \\
Null & 35 & 47 & 1 & 0.455 \\
GSTP1 I/I & 73 & 85 & $1.20(0.77-1.87)$ & 0.956 \\
IN & 99 & 96 & $1.04(0.52-2.04)$ & \\
V/N & 24 & 27 & & \\
\hline
\end{tabular}

of GSTA1 genotypes A / B or B / B. Unfortunately, we do not have data on tobacco use to perform analyses similar to those of Komiya et al. (14). Association studies with prostate cancer GSTA1 are rare, but they were also conducted for other types of cancer. A recent study found an association of the A / A genotype with the risk of gastric cancer in the Vietnamese population $(\mathrm{OR}=4.3,95 \% \mathrm{CI}=$ 1.2 to 17) (27). Genotypes related to reduced expression of GSTA1 (GSTA1 A / B and B / B) were associated with breast cancer, especially among women smokers (OR $=1.89,95 \% \mathrm{CI}=1.09-3.25)$ and those with lower consumption of cruciferous vegetables ( $\mathrm{OR}=1.73,95 \% \mathrm{CI}=1.10$ to 2.72$)$ (28). Little is known about the influence of the GSTA1 polymorphism in the prostate. However, the observation that the expression of this enzyme is increased in situations involving oxidative stress and proliferative hyperplasia associated with chronic inflammation (29) and is reduced in tumors of the prostate intraepithelial reinforce the idea of the possible GSTA1 involvement in carcinogenesis of prostate cancer (30).

In the present study, the distribution of genotype frequencies for GSTM1, GSTT1, and GSTP1 I105V polymorphisms showed no differences between the groups of cases and controls. Risk analysis detected no statistically significant association between these polymorphisms and prostate cancer, suggesting that they do not influence the risk of developing PCa in the Brazilian population (Table-2). For GSTT1 and GSTP1 I105V polymorphisms, some previous studies also reported no association with PCa corroborating our results $(6,14,31-33)$. We found only one study in the Brazilian population, conducted in Sao Paulo, which examined the relationship of GSTT1 and GSTP1 I105V polymorphisms with the risk of PCa (32). The authors also looked at variables such as dietary habits, alcohol consumption, smoking, skin color, among other factors in 225 subjects (125 patients with $\mathrm{PCa}$ and 100 patients with benign prostatic hyperplasia (BPH), used as controls). Even after stratification of the population for these variables, Lima et al. (32) found no association of these polymorphisms with PCa. A meta-analysis (33) involving 22 studies with the GSTT1 polymorphism (totaling 4,564 cases and 4,552 controls) and 24 studies with the GSTP1 I105V polymorphism (totaling 5,301 cases and 5,621 controls) also showed no association of these polymorphisms with $\mathrm{PCa}$ ( $\mathrm{OR}=1.05,95 \% \mathrm{CI}=0.86$ to 1.27 and $\mathrm{OR}=1.06$, $95 \% \mathrm{CI}=0.91$ to 1.24 , respectively). Significant associations of alleles GSTT1 and GSTP $1{ }^{*} 0$ * $105 \mathrm{~V}$ 
Table 4 - Comparison of allelic polymorphisms of GSTA1, GSTM1, GSTT1 and GSTP1 I105V in the study population and different populations

\begin{tabular}{|c|c|c|c|}
\hline GSTA1 & & & \\
\hline Population ( $\mathrm{n}^{0}$ of alelles) & GSTA1*A (\%) & GSTA1 *B (\%) & $\mathrm{p}$ \\
\hline This study ** (398) & $251(63)$ & $147(37)$ & - \\
\hline Caucasians ${ }^{\mathrm{a}}$ (EUA) (162) & $92(57)$ & $70(43)$ & 0.166 \\
\hline Afro-Americansa (EUA) (126) & $81(64)$ & $45(36)$ & 0.804 \\
\hline Japanese $^{\mathrm{b}}(588)$ & $526(89)$ & $62(11)$ & $<0.001$ \\
\hline \multicolumn{4}{|l|}{ GSTP1 I105V } \\
\hline Population ( $n^{0}$ of alelles) & Ile (\%) & Val (\%) & $\mathrm{p}$ \\
\hline This study* (808) & $511(63)$ & $297(37)$ & - \\
\hline Rio de Janeiro ${ }^{\complement}$ (Brazil) (1182) & $813(69)$ & $369(31)$ & 0.01 \\
\hline São Paulo (Brazil)d (442) & $303(68)$ & $139(32)$ & 0.06 \\
\hline Caucasianse (Eslováquia) (456) & $333(73)$ & $123(27)$ & $<0.001$ \\
\hline Afro-Americans ${ }^{\dagger}$ (EUA) (1144) & $646(57)$ & $498(43)$ & 0.003 \\
\hline Japonese $^{\mathrm{b}}(582)$ & $493(85)$ & $89(15)$ & $<0.001$ \\
\hline \multicolumn{4}{|l|}{ Genotype GSTM1 } \\
\hline Population ( $\mathrm{n}^{0}$ of individuals) & POSITIVE (\%) & NULL (\%) & $\mathrm{p}$ \\
\hline This study* $(400)$ & $233(58)$ & $167(42)$ & - \\
\hline Rio de Janeiroc (Brazil) (591) & $342(58)$ & $249(42)$ & 0.905 \\
\hline São Paulod (Brazil) (221) & $120(54)$ & $101(46)$ & 0.341 \\
\hline Caucasians ${ }^{9}$ (Portugual) (325) & $157(48)$ & $168(52)$ & 0.007 \\
\hline Afro-Americans ${ }^{\dagger}$ (EUA) (578) & $441(76)$ & $137(24)$ & $<0.001$ \\
\hline Japonese $^{\mathrm{b}}(474)$ & $224(47)$ & $250(53)$ & $<0.001$ \\
\hline \multicolumn{4}{|l|}{ Genotype GSTT1 } \\
\hline Population ( $\mathrm{n}^{0}$ of individuals) & POSITIVE (\%) & NULL (\%) & $\mathrm{p}$ \\
\hline This study* (404) & $322(80)$ & $82(20)$ & - \\
\hline Rio de Janeiro` (Brazil) (591) & $441(75)$ & $150(25)$ & 0.062 \\
\hline São Paulod (Brazil) 221 & $178(80)$ & $43(20)$ & 0.802 \\
\hline Caucasians ${ }^{9}$ (Portugual) (329) & $254(77)$ & $75(23)$ & 0.412 \\
\hline Afro-Americans ${ }^{\dagger}$ (EUA) (584) & $482(83)$ & $102(17)$ & 0.261 \\
\hline Japonese $^{b}(288)$ & $149(52)$ & $139(48)$ & $<0.001$ \\
\hline
\end{tabular}

Reference population; **Reference population = control group in this study; a39; b14; c16; d40; e20; f6; g41. 
with PCa were detectable only after correlation with other factors. For example, Komiya et al. (14) showed an association between PCa and the GSTT1 null genotype, only when the sample was stratified for smokers and non-smokers. The association was observed for the group of smokers: $\mathrm{OR}=1.68,95 \%$ $\mathrm{CI}=1.06$ to 2.68. Regarding the GSTP1 I105V polymorphism, Lavender et al. (6) showed that the genotype Val / Val was significantly associated with $\mathrm{PCa}$ only when considered in conjunction with the positive GSTM1 genotype (OR $=2.11,95 \% \mathrm{CI}=$ 1.07 to 4.16). Another study (31) showed that the Val / Val genotype was associated with an increased risk of $\mathrm{PCa}(\mathrm{OR}=1.85,95 \% \mathrm{CI}=1.19$ to 2.89 ) in Americans exposed to aromatic hydrocarbons (PAH). For the GSTM1 polymorphism, for example, Agalliu et al. (34) found an increased risk of PCa for the GSTM1 null genotype in U.S. Caucasians ( $\mathrm{OR}=1.54,95 \% \mathrm{CI}=1.19$ to 2.01$)$. Subsequently, a meta-analysis of a sample of 4,564 cases and 5,464 controls also showed an increase of 1.3 times the risk for $\mathrm{PCa}(\mathrm{OR}=1.33,95 \% \mathrm{CI}=1.15$ to 1.55$)$ in individuals with the GSTM1 null genotype (33).

The differences observed in susceptibility studies can be attributed to several factors such as sample size, differences in exposure to biological, chemical, or physical differences in genetic profile and among populations. The evaluation of the combined effects of other susceptibility factors, including other polymorphisms, in a larger study population, could help determine the actual genetic role in the development of PCa.

Variations in the frequencies of polymorphisms in the same population and among different ethnic groups (Table-3) reinforce the importance of being careful in planning epidemiological studies on the role of these polymorphisms in modulating susceptibility to cancer and other diseases. Our results show that GST genotype frequencies in the human population differ among ethnic and geographic groups. Interestingly, the observed frequencies quoted for the Brazilian population are average values of the frequencies found in Caucasians and Africans (Table-3), corroborating data on the mixing of these two dominant groups in southeastern Brazil (35).

Studies in other regions of the country and with a larger sample size are needed to confirm our results; however, we believe that the identification of the genotypic profile of the sample certainly contributes important information for the identification and reassessment of the role of these polymorphisms in a Brazilian population.

\section{CONCLUSIONS}

This is the first study that reports the genotypic frequency of the GSTA1 polymorphism and its association with PCa in a Brazilian population cohort. The distribution of genotype frequencies for GSTM1, GSTT1, and GSTP1 I105V polymorphisms were not associated with risk of prostate cancer in the study sample. The distribution of allele and genotype frequencies of GSTA1, GSTM1, GSTT1 and GSTP1 I105V polymorphisms was statistically different from that of most of the populations compared, showing that a deeper study more specific to the Brazilian population is necessary to design preventive strategies to fight PCa and therapeutic follow-up differentiated from those for other populations.

\section{ABBREVIATIONS}

FIOCRUZ = Fundação Oswaldo Cruz

GSTA1 = glutathione S-transferase Alpha 1

GSTM1 = glutathione S-transferase Mu 1

GSTP1 = glutathione S-transferase Pi 1

GSTT1 = glutathione S-transferase Theta 1

HMK = Mario Kroeff Hospital

INCA $=$ Brazilian National Cancer Institute

$\mathrm{PCa}=$ Prostate cancer

PCR = Polymerase Chain Reaction

PCR-RFLP = Restriction Fragment Length Polymorphism

SNP = Single Nucleotide Polymorphisms

\section{ACKNOWLEDGEMENTS}

This research was supported by INCA/ FIOCRUZ Agreement and Fundação de Amparo à Pesquisa do Rio de Janeiro (FAPERJ). The authors thank the Coordenação de Aperfeiçoamento de Pessoal de Ensino Superior (CAPES) for supporting Renata Almeida de Sá fellowship. 


\section{CONFLICT OF INTEREST}

\author{
None declared.
}

\section{REFERENCES}

1. World Cancer Report, 2008. World Health Organization. International Agency for Research on Cancer, Lyon. 2009.

2. Parkin DM, Bray F, Ferlay J, Pisani P: Global cancer statistics, 2002. CA Cancer J Clin. 2005; 55: 74-108.

3. INCA (Instituto Nacional do Câncer). Ministério da Saúde, Brasil. Available at: http://www.inca.gov.br. Acessed in March 10, 2014.

4. Hughes C, Murphy A, Martin C, Sheils O, O'Leary J: Molecular pathology of prostate cancer. J Clin Pathol. 2005; 58: 673-84.

5. Srivastava DS, Mandhani A, Mittal B, Mittal RD: Genetic polymorphism of glutathione S-transferase genes (GSTM1, GSTT1 and GSTP1) and susceptibility to prostate cancer in Northern India. BJU Int. 2005; 95: 170-3.

6. Lavender NA, Benford ML, VanCleave TT, Brock GN, Kittles $\mathrm{RA}$, Moore JH, et al.: Examination of polymorphic glutathione S-transferase (GST) genes, tobacco smoking and prostate cancer risk among men of African descent: a case-control study. BMC Cancer. 2009; 9: 397.

7. Morel F, Rauch C, Coles B, Le Ferrec E, Guillouzo A: The human glutathione transferase alpha locus: genomic organization of the gene cluster and functional characterization of the genetic polymorphism in the hGSTA1 promoter. Pharmacogenetics. 2002; 12: 277-86.

8. Sergentanis TN, Economopoulos KP: GSTT1 and GSTP1 polymorphisms and breast cancer risk: a meta-analysis. Breast Cancer Res Treat. 2010; 121: 195-202.

9. Coughlin SS, Hall IJ: A review of genetic polymorphisms and prostate cancer risk. Ann Epidemiol. 2002; 12: 182-96.

10. White DL, Li D, Nurgalieva Z, El-Serag HB: Genetic variants of glutathione S-transferase as possible risk factors for hepatocellular carcinoma: a HuGE systematic review and meta-analysis. Am J Epidemiol. 2008; 167: 377-89.

11. Zupa A, Sgambato A, Bianchino G, Improta G, Grieco V, LA Torre G, et al.: GSTM1 and NAT2 polymorphisms and colon, lung and bladder cancer risk: a case-control study. Anticancer Res. 2009; 29: 1709-14.

12. Kelada SN, Kardia SL, Walker AH, Wein AJ, Malkowicz SB, Rebbeck TR: The glutathione S-transferase-mu and -theta genotypes in the etiology of prostate cancer: genotypeenvironment interactions with smoking. Cancer Epidemiol Biomarkers Prev. 2000; 9: 1329-34.

13. Hatagima A: Genetic polymorphisms and metabolism of endocrine disruptors in cancer susceptibility. Cad Saude Publica. 2002; 18: 357-77.
14. Komiya $\mathrm{Y}$, Tsukino $\mathrm{H}$, Nakao $\mathrm{H}$, Kuroda $\mathrm{Y}$, Imai $\mathrm{H}$, Katoh T: Human glutathione S-transferase A1, T1, M1, and P1 polymorphisms and susceptibility to prostate cancer in the Japanese population. J Cancer Res Clin Oncol. 2005; 131: 238-42.

15. Kwon DD, Lee JW, Han DY, Seo IY, Park SC, Jeong HJ, et al.: Relationship between the Glutathione-S-Transferase P1, M1, and T1 Genotypes and Prostate Cancer Risk in Korean Subjects. Korean J Urol. 2011; 52: 247-52.

16. Rossini A, Rapozo DC, Amorim LM, Macedo JM, Medina R, Neto JF, et al.: Frequencies of GSTM1, GSTT1, and GSTP1 polymorphisms in a Brazilian population. Genet Mol Res. 2002; 1: 233-40.

17. Moyer AM, Salavaggione OE, Wu TY, Moon I, Eckloff BW, Hildebrandt MA, et al.: Glutathione s-transferase p1: gene sequence variation and functional genomic studies. Cancer Res. 2008; 68: 4791-801.

18. Zimniak P, Nanduri B, Pikuła S, Bandorowicz-Pikuła J, Singhal SS, Srivastava SK, et al.: Naturally occurring human glutathione S-transferase GSTP1-1 isoforms with isoleucine and valine in position 104 differ in enzymic properties. Eur J Biochem. 1994; 224: 893-9.

19. Mittal RD, Srivastava DS, Mandhani A, Kumar A, Mittal B: Polymorphism of GSTM1 and GSTT1 genes in prostate cancer: a study from North India. Indian J Cancer. 2004; 41: 115-9.

20. Sivonová M, Waczulíková I, Dobrota D, Matáková T, Hatok J, Racay $\mathrm{P}$, et al.: Polymorphisms of glutathione-S-transferase M1, T1, P1 and the risk of prostate cancer: a case-control study. J Exp Clin Cancer Res. 2009; 28: 32.

21. Zar Jerrold H. Biostatistical Analysis. Editor Prentice Hall; Fourth Edition, 1999.

22. Sambrook J, Russell DW: Molecular Cloning - A Laboratory Manual. NewYork: Cold Spring Harbor Laboratory Press. 2001.

23. Maniatis T, Sambrook J and Fritsch E F. Molecular cloning : a laboratory. Cold Spring Harbor Laboratory, Cold Spring Harbor, NY. 1982.

24. Listowsky I, Abramovitz M, Homma H, Niitsu Y: Intracellular binding and transport of hormones and xenobiotics by glutathione-S-transferases. Drug Metab Rev. 1988; 19: 305-18.

25. Schaid DJ: The complex genetic epidemiology of prostate cancer. Hum Mol Genet. 2004; 13: R103-21.

26. Smith CJ, Perfetti TA, Rumple MA, Rodgman A, Doolittle DJ: "IARC Group 2B carcinogens" reported in cigarette mainstream smoke. Food Chem Toxicol. 2001; 39: 183-205.

27. Nguyen TV, Janssen MJ, van Oijen MG, Bergevoet SM, te Morsche RH, van Asten $\mathrm{H}$, et al.: Genetic polymorphisms in GSTA1, GSTP1, GSTT1, and GSTM1 and gastric cancer risk in a Vietnamese population. Oncol Res. 2010; 18: 349-55.

28. Ahn J, Gammon MD, Santella RM, Gaudet MM, Britton JA, Teitelbaum SL, et al.: Effects of glutathione S-transferase A1 (GSTA1) genotype and potential modifiers on breast cancer risk. Carcinogenesis. 2006; 27: 1876-82. 
29. Coles BF, Morel F, Rauch C, Huber WW, Yang M, Teitel CH et al.: Effect of polymorphism in the human glutathione S-transferase A1 promoter on hepatic GSTA1 and GSTA2 expression. Pharmacogenetics. 2001; 11: 663-9.

30. Parsons JK, Nelson CP, Gage WR, Nelson WG, Kensler TW, De Marzo AM: GSTA1 expression in normal, preneoplastic, and neoplastic human prostate tissue. Prostate. 2001; 49: 30-7.

31. Rybicki BA, Neslund-Dudas C, Nock NL, Schultz LR, Eklund $\mathrm{L}$, Rosbolt J, et al.: Prostate cancer risk from occupational exposure to polycyclic aromatic hydrocarbons interacting with the GSTP1 Ile105Val polymorphism. Cancer Detect Prev. 2006; 30: 412-22.

32. Lima MM Jr, Oliveira MN, Granja F, Trindade AC, De Castro Santos LE, Ward LS: Lack of association of GSTT1, GSTM1, GST01, GSTP1 and CYP1A1 polymorphisms for susceptibility and outcome in Brazilian prostate cancer patients. Folia Biol (Praha). 2008; 54: 102-8.

33. Mo Z, Gao Y, Cao Y, Gao F, Jian L: An updating meta-analysis of the GSTM1, GSTT1, and GSTP1 polymorphisms and prostate cancer: a HuGE review. Prostate. 2009; 69: 662-88.

34. Agalliu I, Lin DW, Salinas CA, Feng Z, Stanford JL: Polymorphisms in the glutathione S-transferase M1, T1, and $\mathrm{P} 1$ genes and prostate cancer prognosis. Prostate. 2006; 66 : 1535-41.

35. Carvalho-Silva DR, Santos FR, Rocha J, Pena SD: The phylogeography of Brazilian Y-chromosome lineages. Am J Hum Genet. 2001; 68: 281-6.

36. Nedelcheva Kristensen V, Andersen TI, Erikstein B, Geitvik G, Skovlund E, Nesland JM, et al.: Single tube multiplex polymerase chain reaction genotype analysis of GSTM1, GSTT1 and GSTP1: relation of genotypes to TP53 tumor status and clinicopathological variables in breast cancer patients. Pharmacogenetics. 1998; 8: 441-7. Erratum in: Pharmacogenetics 1999; 9: following 127.
37. Pemble S, Schroeder KR, Spencer SR, Meyer DJ, Hallier $\mathrm{E}$, Bolt HM, et al.: Human glutathione S-transferase theta (GSTT1): cDNA cloning and the characterization of a genetic polymorphism. Biochem J. 1994; 300: 271-6.

38. Hatagima A, Costa EC, Marques CF, Koifman RJ, Boffetta P, Koifman S: Glutathione S-transferase polymorphisms and oral cancer: a case-control study in Rio de Janeiro, Brazil. Oral Oncol. 2008; 44: 200-7.

39. Ning B, Wang C, Morel F, Nowell S, Ratnasinghe DL, Carter W, et al:: Human glutathione S-transferase A2 polymorphisms: variant expression, distribution in prostate cancer cases/ controls and a novel form. Pharmacogenetics. 2004; 14: 3544

40. Burim RV, Canalle R, Martinelli Ade L, Takahashi CS: Polymorphisms in glutathione S-transferases GSTM1, GSTT1 and GSTP1 and cytochromes P450 CYP2E1 and CYP1A1 and susceptibility to cirrhosis or pancreatitis in alcoholics. Mutagenesis. 2004; 19: 291-8.

41. Medeiros R, Vasconcelos A, Costa S, Pinto D, Ferreira P, Lobo F, et al.: Metabolic susceptibility genes and prostate cancer risk in a southern European population: the role of glutathione S-transferases GSTM1, GSTM3, and GSTT1 genetic polymorphisms. Prostate. 2004; 58: 414-20.

Correspondence address:
Gilda Alves Brown, Biologist, PhD
Laboratory of Applied Genetics, Hematology Service
Brazilian National Institute of Cancer
Pç. da Cruz Vermelha, 23, 6 Floor
Rio de Janeiro, RJ, 20230-130, Brasil
Telephone: +55 21 3207-1622
E-mail: gbrown@inca.gov.br

